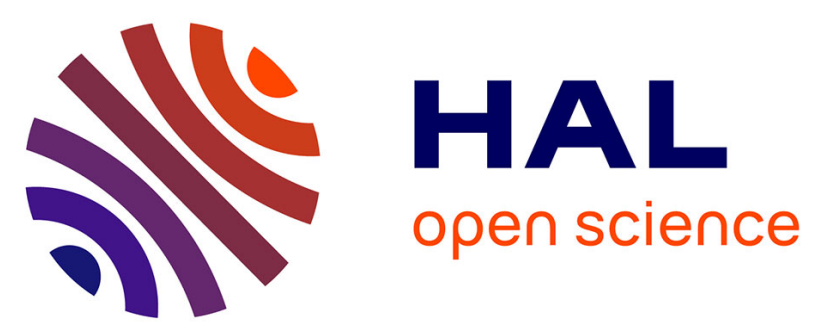

\title{
The GH130 family of mannoside phosphorylases contains glycoside hydrolases that target beta-1,2 mannosidic linkages in Candida mannan
}

Fiona Cuskin, Arnaud Baslé, Simon Ladeveze, Alison Day, Harry Gilbert, Gideon Davies, Gabrielle Veronese, Elisabeth Lowe

\section{To cite this version:}

Fiona Cuskin, Arnaud Baslé, Simon Ladeveze, Alison Day, Harry Gilbert, et al.. The GH130 family of mannoside phosphorylases contains glycoside hydrolases that target beta-1,2 mannosidic linkages in Candida mannan. Journal of Biological Chemistry, 2015, 290 (41), 10.1074/jbc.M115.681460 . hal-01184120v2

\author{
HAL Id: hal-01184120 \\ https://hal.science/hal-01184120v2
}

Submitted on 8 Mar 2017

HAL is a multi-disciplinary open access archive for the deposit and dissemination of scientific research documents, whether they are published or not. The documents may come from teaching and research institutions in France or abroad, or from public or private research centers.
L'archive ouverte pluridisciplinaire HAL, est destinée au dépôt et à la diffusion de documents scientifiques de niveau recherche, publiés ou non, émanant des établissements d'enseignement et de recherche français ou étrangers, des laboratoires publics ou privés.

\section{(c)(1)}

Distributed under a Creative Commons Attribution| 4.0 International License 


\title{
The GH130 family of mannoside phosphorylases contains glycoside hydrolases that target $\beta-1,2$ mannosidic linkages in Candida mannan
}

\author{
Fiona Cuskin ${ }^{1}$, Arnaud Baslé ${ }^{1}$, Simon Ladevèze ${ }^{2,3,4}$, Alison M. Day ${ }^{1}$, Harry J. Gilbert ${ }^{1 *}$, Gideon J. \\ Davies $^{5}$, Gabrielle Potocki-Véronèse ${ }^{2,3,4}$ and Elisabeth C. Lowe ${ }^{1 *}$
}

\begin{abstract}
${ }^{1}$ Institute for Cell and Molecular Biosciences, The Medical School Newcastle University, Newcastle upon Tyne NE2 4HH, U.K.; ${ }^{2}$ Université de Toulouse, INSA/UPS/INP, LISBP, 135 Avenue de Rangueil, F-31077 Toulouse, France; ${ }^{3}$ CNRS, UMR5504, F-31400 Toulouse, France ; ${ }^{4}$ INRA, UMR792 Ingénierie des Systèmes Biologiques et des Procédés, F-31400 Toulouse, France ; ${ }^{5}$ York Structural Biology Laboratory, Department of Chemistry, University of York, York YO10 5DD, U.K.
\end{abstract}

Running title: GH130 $\beta$-mannosidases

*To whom correspondence should be addressed: ${ }^{1}$ Institute for Cell and Molecular Biosciences, The Medical School Newcastle University, Newcastle upon Tyne NE2 4HH, U.K. Elisabeth C. Lowe Tel.: +44-(0)1912228947, Fax: +44-(0)1912228947, e.mail: Elisabeth.lowe@ @cl.ac.uk or Harry J. Gilbert Tel.: +44-(0)1912228800, Fax: +44-(0)1912228947, e.mail: harry.gilbert@ncl.ac.uk

Keywords: Glycoside hydrolase; phosphorylase; cell wall; yeast; X-ray crystallography; gut symbionts.

Background: A cohort of a family of mannose phosphorylases lack phosphate binding residues suggesting they display nonphosphorylase activities.

Results: The non-phosphorylase enzymes were shown to be $\beta$-mannosidases.

Conclusion: Replacing basic phosphate binding residues with carboxylic amino acids converts mannoside phosphorylases into glycoside hydrolases

Significance: Functional phylogeny can be used to distinguish between closely related glycan phosphorylases and glycoside hydrolases

\section{ABSTRACT}

The depolymerization of complex glycans is an important biological process that is of considerable interest to environmentally relevant industries. $\beta$-mannose is a major component of plant structural polysaccharides and eukaryotic N-glycans. These linkages are primarily cleaved by glycoside hydrolases, although a family of glycoside phosphorylases, GH130, have also been shown to target $\beta-1,2$ and $\beta-1,4$ mannosidic linkages. In these phosphorylases bond cleavage was mediated by a single displacement reaction in which phosphate functions as the catalytic nucleophile. A cohort of GH130 enzymes, however, lack the conserved basic residues that bind the phosphate nucleophile, and it was proposed that these enzymes function as glycoside hydrolases. Here we show that two Bacteroides enzymes, BT3780 and BACOVA_03624, which lack the phosphate binding residues are indeed $\beta$-mannosidases that hydrolyse $\beta$-1,2-mannosidic linkages through an inverting mechanism. As the genes encoding these enzymes are located in genetic loci that orchestrate the depolymerisation of yeast $\alpha$-mannans, it is likely that the two enzymes target the $\beta-1,2-$ mannose residues that cap the glycan produced by Candida albicans. The crystal structure of BT3780 in complex with mannose bound in the -1 and +1 subsites showed a pair of glutamates, Glu227 and Glu268 hydrogen bond to 01 of $\alpha$-mannose, and either of these residues may function as the catalytic base. The candidate catalytic acid and the other residues that interact with the active site mannose are conserved in both GH130 mannoside phosphorylases and $\beta$ 1,2-mannosidases. Functional phylogeny identified a conserved lysine, Lys199 in BT3780, as a key specificity determinant for $\beta$-1,2-mannosidic linkages.

\section{INTRODUCTION}

The microbial recycling of complex glycans is an important biological process that plays a central role in the carbon cycle. The process is 
also of significant industrial interest particularly in the biofuel and biorefinery sectors (1). The cleavage of the glycosidic bonds in complex glycans is primarily mediated by glycoside hydrolases, although polysaccharide lyases and, to a lesser extent, glycan phosphorylases contribute to the degradative process (2). These carbohydrate active enzymes or CAZymes are grouped into sequence based families in the CAZy database (3). Although enzymes in the same family may display different substrate specificities, the fold, catalytic mechanism and catalytic apparatus is conserved in the vast majority of the 133 glycoside hydrolase families (GHs) (3).

Mannose (Man)-containing glycans are important components of the secondary cell walls of many plants. These plant mannans are homopolymers of $\beta-1,4-$ Man units that can be decorated at $\mathrm{O6}$ with $\alpha$-galactose residues and are thus further defined as galactomannans, Fig. 1A. In glucomannans the backbone consists of random sequences of $\beta$-1,4-linked Man and glucose (Glc) residues (4). The core of mammalian $\mathrm{N}$-glycans contains a conserved Man- $\beta 1,4-G l c N A c$ linkage, while $\alpha$-linked Man units are commonly found elsewhere in these structures (5), Fig. 1B. The proteins in yeast cell walls contain particularly complex $\mathrm{N}$ glycans referred to as $\alpha$-mannans in which the core $\mathrm{N}$-glycan is extended by $\sim 200 \alpha-1,6-\mathrm{Man}$ units that are also decorated with $\alpha$-linked Man side chains (6). In some yeasts, such as the human pathogen Candida albicans, $\beta-1,2-$ mannose residues cap the $\alpha$-mannans side chains, and extended $\beta-1,2-$ Man chains are attached to the $\alpha$-mannan via phosphate bridges, Fig. 1C. $\beta-1,2-$ Man units which play an important role in detection of $C$. albicans by the innate immune system via the C-type lectin, Galectin-3 (7,8). $\beta$-1,2-Mannans also fulfil an important storage role in Leishmania parasites (9). Plant cell wall mannans are hydrolysed by GH5, GH26 and GH113 $\beta$-mannanases, while $\beta-1,4-$ mannosides are targeted primarily by enzymes in GH2 and GH5 (see Ref. (2) for review). These enzymes display a TIM-barrel fold and cleave glycosidic linkages by a double displacement mechanism leading to retention of anomeric configuration (10-12).

GH130 contains exo-acting $\beta$-mannoside phosphorylases that cleave the $\beta-1,2$ and $\beta-1,4$ mannosyl linkages between Man and Man, Glc or GlcNAc residues (13-18). The phosphate nucleophile attacks $\mathrm{C} 1$ of the Man in the active site below the $\alpha$-face of the pyranose ring leading to phosphorolysis. The single displacement mechanism displayed by these phosphorylases leads to inversion of anomeric configuration (16). The phosphate is positioned in the active site through polar interactions with three basic residues that are highly conserved within GH130 $(19,20)$. A subset of GH130 members, however, lacks these basic residues and it was proposed that these enzymes may function as glycoside hydrolases cleaving mannosidic bonds through a hydrolytic reaction (18) .

To test the GH130 glycoside hydrolase hypothesis the structure and biochemical properties of a representitive GH130 enzyme were determined. The enzyme, BT3780, which lacks the canonical phosphate-binding basic residues, is up-regulated by the dominant human gut bacterium Bacteroides thetaiotaomicron (21) in response to yeast mannan. BT3780 is encoded by a polysaccharide utilitzation locus (PUL) in the $B$. thetaiotaomicron genome that orchestrates the depolymerisation of yeast mannan. A similar PUL encodes BACOVA_03624, one of seven GH130 proteins of the human gut symbiont B. ovatus ATCC 8483. The crystal structure of BACOVA_03624 was released in the Protein Data Bank (PDB) in 2011 (PDB code $3 \mathrm{QC} 2$ ) but, to date, no function had been attributed to this protein. Thus, the likely substrate for these enzymes is the Man- $\beta 1,4$ GlcNAc linkage at the base of $\mathrm{N}$-glycans or the $\beta$-1,2-Man units that cap the side chain of some fungal $\alpha$-mannans. The data, presented here, showed that BT3780 and BACOVA_03624 are exo-acting glycoside hydrolase that cleave Man- $\beta 1,2-$ Man linkages using water, and not phosphate, as the nucleophile in a single displacement reaction. The 3-D structure of the enzymes in concert with function phylogeny identified motifs within GH130 that delineate glycoside hydrolases and enzymes, both hydrolases and phosphorylases, which target $\beta$ 1,2-mannosidic linkages

\section{MATERIALS AND METHODS \\ Cloning, expression and purification of Bacteroides GH130 enzymes: BT3780 was}


amplified from $B$. thetaiotaomicron genomic DNA and cloned into pET28a with an Nterminal His 6 tag using NheI and XhoI restriction sites. To generate DNA encoding the sequence of the protein was used as template for gene synthesis with codon optimization for Escherichia coli heterologous production (Biomatik, Cambridge, Ontario, Canada), and was subsequently cloned into the pET28a vector. The two proteins were expressed in $E$. coli BL21 cells transformed with the appropriate recombinant plasmids. The recombinant $E$. coli strains were cultured in Luria broth supplemented with $50 \mu \mathrm{g} / \mathrm{ml}$ kanamycin. Cultures cells were grown at $37^{\circ} \mathrm{C}$ to mid-log phase and induced with $1 \mathrm{mM}$ Isopropyl $\beta$-D-1-thiogalactopyranoside at 16 ${ }^{\circ} \mathrm{C}$ overnight. Cells were harvested by centrifugation $5000 \mathrm{rpm}$ for $5 \mathrm{~min}$ and resuspended in $20 \mathrm{mM}$ Tris- $\mathrm{HCl}$ buffer, $\mathrm{pH} 8.0$, containing $300 \mathrm{mM} \mathrm{NaCl}$ (Buffer A). Cells were lysed by sonication and the cell free extract recovered by centrifugation at 13000 rpm for 30 min. BT 3780 was purified from the cell free extract using immobilised metal affinity chromatography (IMAC) using Talon $^{\mathrm{TM}}$, a cobalt-based matrix. Proteins were eluted from the column in Buffer A containing $100 \mathrm{mM}$ imidazole. For crystallization trials IMAC purified protein was concentrated and further purified by gel filtration chromatography using a Superdex S200 16/600 column equilibrated in Buffer B.

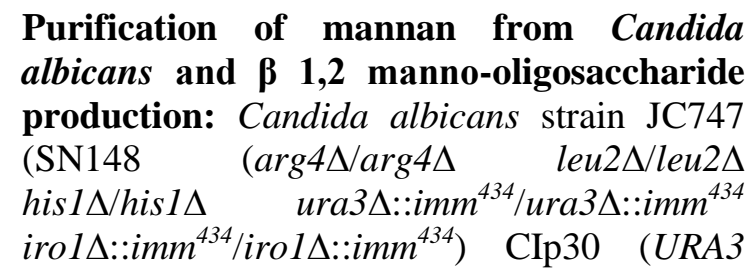
HIS1 ARG4)was grown in YPD medium (22) at $30^{\circ} \mathrm{C}$. Mannan was purified from $C$. albicans cells as follows. Cell pellets were resuspended in MilliQ water and autoclaved at $121^{\circ} \mathrm{C}$ for 3 h. Mannan was precipitated with 4 volumes of ice cold ethanol. Precipitate was pelleted by centrifugation at $5000 \mathrm{rpm}$ for $10 \mathrm{~min}$, resuspended in and dialysed overnight against MilliQ water and freeze dried to remove residual ethanol. To produce $\beta 1,2$ mannooligosaccharides, Candida mannan at $5 \mathrm{mg} / \mathrm{ml}$ was acid hydrolysed with $10 \mathrm{mM} \mathrm{HCl}$ at $100{ }^{\circ} \mathrm{C}$ for $1 \mathrm{~h}$. The acid hydrolysis was neutralised with sodium hydroxide and oligosaccharides were purified by size exclusion chromatography using P2 Bio-Gel P2 (BioRad) columns, the oligosaccharides were eluted in MilliQ water.

Enzyme assays: All enzyme assays unless otherwise stated were carried out in $20 \mathrm{mM}$ Hepes-Na buffer, pH 7.5., containing $100 \mathrm{mM}$ $\mathrm{NaCl}$. Assays were carried out with $1 \mu \mathrm{M}$ BT 3780 against $1 \mathrm{mg} / \mathrm{ml}$ substrate at $37{ }^{\circ} \mathrm{C}$ for up to $16 \mathrm{~h}$. Aliquots were taken over a $16 \mathrm{~h}$ time course, and samples and products were assessed by thin layer chromatography (TLC) and high pressure anion exchange chromatography with pulsed amperometric detection (HPAECPAD). Sugars were separated on a Carbopac PA200 guard and analytical column in an isocratic programme of $100 \mathrm{mM}$ sodium hydroxide. Sugars was detected using the carbohydrate standard quad waveform for electrochemical detection at a gold working electrode with an $\mathrm{Ag} / \mathrm{AgCl} \mathrm{pH}$ reference electrode. Kinetic parameters were determined using the D-mannose detection kit from Megazyme International, measuring the release of mannose at absorbance of $340 \mathrm{~nm}$. To determine kinetic parameters $2 \mu \mathrm{M}$ of BT3780 was assayed against varying concentrations of polysaccharide or oligosaccharides between (0.1-2 mM). Mannose release was measured and the values were plotted using linear regression giving $k_{\mathrm{cat}} / K_{\mathrm{m}}$ as the slope of the line. Mutants were assessed for activity against $C$. albicans mannan at $1 \mathrm{mg} / \mathrm{ml}$ with varying enzyme concentrations between 1-200 $\mu \mathrm{M}$. All assays were carried out in triplicate.

NMR spectroscopy: Reaction buffer 10x (1x, $20 \mathrm{mM}$ sodium phosphate buffer $\mathrm{pH} 7.5$ containing $100 \mathrm{mM} \mathrm{NaCl}$ ) and $C$. albicans mannan were freeze dried and resuspended in $\mathrm{D}_{2} \mathrm{O}$ twice prior to the experiment. BT3870 was transferred to reaction buffer in $\mathrm{D}_{2} \mathrm{O}$ by extensive buffer exchange. Initial spectra were recorded of $900 \mu 110 \mathrm{mg} \mathrm{ml}^{-1}$ C. albicans mannan in reaction buffer before initiating the reaction by the addition of $100 \mu \mathrm{BT} 3780$ (final concentration $30 \mu \mathrm{M}) .{ }^{1} \mathrm{H}$ NMR spectra were recorded in $\mathrm{D}_{2} \mathrm{O}$ on a Bruker Avance III HD $500 \mathrm{MHz}$ NMR spectrometer operating at $500.15 \mathrm{MHz}$ at regular intervals. The chemical shift is quoted in ppm relative to tetramethylsilane and each spectrum was acquired with 16 scans. Spectra of mannose and mannose-1-phosphate $(2.5 \mathrm{mM}$ in reaction buffer) standards were also recorded. 
Crystallography: BT3780 purified by IMAC and size exclusionaffinity chromatography was concentrated in a $30 \mathrm{kDa}$ cut-off centrifugal concentrator and buffer exchanged into $\mathrm{H}_{2} \mathrm{O}$ prior to crystallisation. Crystals were obtained in $2.2 \mathrm{M} \mathrm{NH}_{4} \mathrm{SO}_{4}$, with $0.3 \mathrm{M}$ mannose in 96 well sitting-drop TTP Labtech plates (200 nl drops). BT3780, at $15 \mathrm{mg} / \mathrm{ml}$. Crystals were cryoprotected with saturated $\mathrm{NH}_{4} \mathrm{SO}_{4}$ and data were collected at Diamond Light Source, U.K., on beamline I04-1 $(\lambda 0.92 \AA)$ at $100 \mathrm{~K}$. The data were integrated with XDS (23) and scaled with Aimless (24). Five percent of observations were randomly selected for the Rfree set. Space group were determined using Pointless (25). The phase problem was solved by molecular replacement using the program Molrep (Vagin 2010) and the PDB search model 3QC2. Initial phases were used in the program Buccaneer (25) to automatically build the model. Solvent molecules were added using COOT (26) and checked manually. The model underwent cycles of model building in COOT (26) and refinement in Refmac (27). All other computing used the CCP4 suite of programs (28).The model was validated using Molprobity (29) and data statistics and refinement details are reported in Table 1. The model was deposited to the PDB databank and given the PDB code 5A7V. Structure representations were made in PyMOL (The PyMOL Molecular Graphics System, Version 1.7.4 Schrödinger, LLC).

\section{RESULTS}

Biochemical properties of BT3780: The genome of $B$. thetaiotaomicron contains three PULs, MAN-PUL1, MAN-PUL2 and MANPUL3, which orchestrate the degradation of yeast $\alpha$-mannan (21). Within MAN-PUL2 is a gene encoding BT3780, a member of CAZy family GH130. This family currently comprises $\beta$-D-mannoside phosphorylases that mediate bond cleavage through a single displacement mechanism with phosphate as the nucleophile, resulting in the inversion of anomeric configuration and the generation of $\alpha$-mannose1-phosphate. Thus the possible linkages in $S$. cerevisiae $\alpha$-mannan targeted by BT3780 are Man- $\beta 1,4-G l c N A c \quad$ (possibly Man- $\beta 1,4-$ GlcNAc- $\beta 1,4-$ GlcNAc) and $\alpha$-Man-1phosphate (where cleavage would then be associated with a reverse phosphorolysis reaction). The data presented in Table 2 shows that BT3780 displayed no exo- or endo-activity against these linkages in the presence or absence of phosphate. Yeast and fungal $\alpha$ mannans are not all identical and in the Candida albicans $\alpha$-mannan the mannose side chains are capped by one or more $\beta-1,2$-mannose units, which are therefore also potential substrates for BT3780. These $\beta 1,2$-mannose linkages are potential substrates for BT3780. Incubation of C. albicans $\alpha$-mannan with BT3780 released a product that co-migrates with mannose on HPAEC and TLC, Fig. 2, suggesting that the enzyme indeed targets these $\beta 1,2$-mannose units. Furthermore, the inability of BT3780 to release mannose from Saccharomyces cerevisiae mannan, which lacks the capping $\beta$ Man residues, is also consistent with this proposed specificity for $\beta 1,2$-mannosyl linkages. The specificity of BT3780 for $\beta-1,2-$ Man linkages was further supported by the observation that 212 and $620 \mu$ moles of mannose were released from $0.5 \mathrm{mg} C$. albicans $\alpha$-mannan by the side chain cleaving $\alpha$ mannosidase, BT3774 (21), before and after treatment of the glycan with BT3780, respectively. Several additional lines of evidence showed that BT3780 generated mannose and not mannose-1-phosphate. Thus, the activity of BT3780 could be monitored by standard mannose detection kits in which mannose-1-phosphate is not a substrate for the linker enzymes (Megazyme International DMannose/D-Fructose/D-Glucose Assay kit); NMR spectra of the sugar released by BT3780 revealed $\mathrm{H}^{1}$ signals corresponding to both the $\alpha$ and $\beta$ anomers of mannose, while the signal for the anomeric hydrogen in mannose-1phosphate, with a chemical shift of 5.28 ppm, was absent, Fig. 3. Thus, the enzyme does not mediate phosphorolysis or reverse phosphorolysis reactions and therefore is not a glycoside phosphorylase. These data instead show that BT3780 is an exo-acting glycoside hydrolase that hydrolyses $\beta 1,2$-mannosidic linkages. The observation that the enzyme displayed no detectable activity against mannose linked $\beta 1,4$-linked to mannose or glucose (in mannans and glucomannans, respectively) or GlcNAc, Table 2, confirms its tight specificity for $\beta-1,2$-mannosidic linkages.

To explore further the specificity of BT3780, the catalytic activity of the enzyme against 
1,2-mannooligosaccharides was determined. The data, Table 2, showed that the enzyme exhibited low activity against the oligosaccharides with a $K_{\mathrm{m}}$ that was too high to quantify, indicating weak affinity for these substrates. Given that the BT3780 displayed similar $k_{\text {cat }} / K_{\mathrm{m}}$ values for oligosaccharides with a degree of polymerization (DP) ranging from 2 to 4 , the enzyme appears to contain only two subsites, -1 and +1 . Phosphate did not influence the hydrolytic activity of BT3780 and mannose1-phosphate did not participate in reverse phosphorolysis reactions with a range of sugars to generate $\beta$-linked disaccharides (data not shown). GH130 mannose-phosphorylases invert the anomeric configuration of the phosphorylated mannose residue generating $\alpha$ mannose-1-phosphate (16). NMR analysis of the reaction products generated by BT3780 was used to determine whether the enzyme also hydrolysed mannosidic linkages through a single displacement (inverting) mechanism. The data, Fig. 3, showed that the initial product was $\alpha$-D-mannose, which subsequently mutarotated to a $2: 1$ ratio of the $\alpha$ - and $\beta$ anomers of the sugar. C. albicans mannan polysaccharide was used as the substrate for the NMR experiment, which contributes a number of other features to the NMR spectra, including a peak at $4.99 \mathrm{ppm}$. The increase of this peak with incubation time likely corresponds to $\alpha$ mannose side chains that are not capped by $\beta$ 1,2 mannosides, which accumulate as digestion with BT3780 proceeds (30). These data show that both the glycoside phosphorylases and the glycoside hydrolases in family GH130 mediate bond cleavage though a single displacement inverting mechanism.

Crystal structure of BT3780: To explore the structural basis for the catalytic activity and specificity of BT3780 the crystal structure of the enzyme was determined. Residues 17-384 (the first 16 residues is a cleaved signal peptide and residue 383 is the $\mathrm{C}$-terminal Pro) were built into the $1.35 \AA$ electron density map, (Table 1, Fig. 4A). The $\beta$-mannosidase displayed a five-bladed $\beta$-propeller fold. Each blade consists of a $\beta$-sheet generally comprising four antiparallel strands, although blade 5 only contained three $\beta$-strands. Blade 4 contains a loop insertion in $\beta$-strand 1 extending from Cys269 to Ala273. The blades are arranged radially around the central axis and are strongly twisted. The $\beta$-sheets from the five blades pack face to face, with hydrophobic interactions and hydrogen bonds as observed for other $\beta$ propeller proteins. The propeller has a cylindrical shape with diameter and height of about $40 \AA$ and is present as a monomer in solution (data not shown). Most $\beta$-propeller proteins are 'closed' by the completion of the $\mathrm{C}$ terminal four-stranded sheet through incorporation of a strand from the $\mathrm{N}$-terminus, or vice versa, colloquially termed 'molecular velcro'. This is believed to provide considerable stabilization to the fold (31). Non-velcroed propellers are rare, having primarily been described only for the seven-bladed prolyloligopeptidase, where the resultant flexibility is believed to facilitate substrate transfer (32). In BT3780 blades 1 and 5 are derived exclusively from $\mathrm{N}$ - and $\mathrm{C}$-terminal sequences, respectively, and thus, no classical "Velcro" is present. There are, however, three hydrogen bonds between the $\mathrm{N}$ - and C-terminal blades. Of more significance is the long $\mathrm{N}$ terminal loop extending from residues 17 to 70 , which makes numerous polar contacts with the C-terminal blade and thus confers considerable stabilization of the protein fold.

BT3780 exhibits structural similarity to a range of proteins that display a 5 -bladed $\beta$-propeller fold, including several members of GH130. The closest homolog used as molecular replacement model is with the $B$. ovatus enzyme BACOVA_03624 (PDB ID code 3QC2; zscore of 66 and an rmsd of $0.4 \AA$ over $357 \mathrm{C} \alpha$ atoms with sequence identity of $86 \%$ ). which was previously shown to crystalize as a monomer. Both proteins are very similar, with identical arrangement of $\beta$-strands in the 5 blades. Inspection of the secondary structure of the only cytoplasmic GH130 B. fragilis $\beta-1,4-$ mannosylglucose phosphorylase BF0772 (PDB code 3 WAS) reveals an extended $\alpha$-helix at the $\mathrm{N}-$ and C-termini. These helices mediate protomer interactions in the $B$. fragilis enzyme leading to a hexameric structure (20). The absence of these helices in BT3780 and BACOVA_03624 explains why these $\beta-1,2-$ mannosidases are monomers, although in the GH130 Man- $\beta 1,4-G l c N A c$ phosphorylase UhgbMP the hexameric structure is mediated by interactions between the $\beta$-propellers (19). 
Active site of BT3780: An extended pocket is located in the centre of the $\beta$-propeller with all five blades contributing to the topology of the pocket. The pocket houses two mannose residues (the crystal structure of BT3780 was obtained in the presence of mannose) and its location corresponds to the active site of BF0772, and thus fulfills the same function in the $B$. thetaiotaomicron enzyme, Fig. $\mathbf{4 b}$. The mannose residue in the +1 subsite (Man2) adopts a classic ${ }^{4} C_{1}$ chair conformation. In the 1 subsite (active site; (33)), however, the mannose (Man1) is in a $B_{2,5} /{ }^{\circ} S_{2}$ conformation, typical of the geometry adopted by the oxocarbenium ion transition state in $\beta$ mannanases and $\beta$-mannosidases, Fig. 4c, $(34,35)$. The interactions between the enzyme and products bound at the -1 and +1 subsites are detailed in Fig. 5. O1 of Man1 makes polar contacts with the side chains of Glu227, Glu268 and Tyr302; O2 interacts with Asp142 and Glu227; O3 forms a hydrogen bond with Asp142 and Asn74; O4 also makes a polar contact with Asn74 and Asp363 forms bidentate interactions with $\mathrm{O} 4$ and $\mathrm{O} 6$. At the +1 subsite Man2 recognition is dominated by Lys199, which interacts with O2, O6 and the endocyclic oxygen; Arg89 makes three hydrogen bonds with $\mathrm{O} 3$ and O4, while Glu141 interacts with $\mathrm{O} 4$ and $\mathrm{O} 6$. At the -1 subsite a cradle of aromatic residues, Tyr302, Tyr338 and Phe344, make hydrophobic interactions with Man1, while at the +1 subsite Trp160 and a few aliphatic residues make apolar contacts with Man2. BT3780 does not make interactions with $\mathrm{O} 1$ of Man2 and thus both the $\alpha$ and $\beta$ anomer are evident. O1 of both anomers of Man2 are pointing directly into solvent explaining why BT3780 can attack the terminal $\beta-1,2-$ Man linkages in highly complex polysaccharides such as mannan in the cell wall of $C$. albicans. Indeed, the solvent exposure of both anomers of Man2 indicates that BT3780 can hydrolyse linkages where the +1 sugar is linked $\alpha$ or $\beta$ to the mannan side chains. This is significant as BT3780 can fully hydrolyse the $\beta$-1,2-Man structures that cap the mannan side chains and thus expose the $\alpha$-linked mannosidic linkages to attack by $\alpha$-mannosidases such as BT3774 (see above). The importance of these active site residues in the activity of BT3780 was explored by site-directed mutagenesis. The data, Table 3, showed that Asp142, Lys199 and Asp363 all played a critical role in catalysis as substitution of these residues led to complete loss in mannosidase activity. The 40-fold reduction in $k_{\text {cat }} / K_{\mathrm{m}}$ of $\mathrm{N} 74 \mathrm{~A}$ against Candida mannan, compared to the wild type enzyme, indicates that Asn74 also contributes to the activity of BT3780. R89A, however, was only 7-fold less active than wild type BT3780 and thus, although Arg89 is highly conserved (see below) and apparently makes several interactions with substrate at the +1 subsite, this residue makes little contribution to the catalytic efficiency of the enzyme.

The catalytic apparatus of BT3780: A distinctive feature of the active site of BT3780 is the lack of residues that could easily fulfil the role of a classical catalytic general acid. Asp142 is the only potential catalytic acid as it is invariant in GH130 (see below) and is closest to the scissile bond. The residue, however, is too distant ( $4.8 \AA$ ) to make direct polar contact with the glycosidic oxygen, Fig. 5. It is possible that this acidic residue donates a proton to the glycosidic oxygen via solvent. It has been proposed that the equivalent residue in the Man- $\beta 1,4-G l c$ and Man- $\beta 1,4-G l c N A c$ phosphorylases BF0772 and UhgbMP (Asp131 and Asp104, respectively) activates a proton relay culminating in the protonation of the glycosidic oxygen $(19,20)$. In this mechanism the glycosidic oxygen abstracts the proton from $\mathrm{O} 3$, which in turn receives a proton from $\mathrm{O} \delta 2$ of the aspartate. Support for this proposal is provided by $\mathrm{BF} 0772$ and UhgbMP in which $\mathrm{O} 3$ of Man1 is within hydrogen bonding distance to $\mathrm{O} 4$ of the Glc and GlcNAc, respectively, which occupy the +1 subsite. The importance of the carboxylate of the aspartate is demonstrated by the catalytically inactive mutant D142N. It should be emphasised that to date only a direct interaction between the catalytic acid and the glycosidic oxygen has been observed. It should be noted, however, that in other glycoside hydrolases the substrate can provide direct catalytic nucleophilic assistance, typically the carbonyl of the $\mathrm{C} 2$ acetamido group in GH18 and $\mathrm{GH} 20 \mathrm{~N}$-acetylglucosaminidases (36), but also the $\mathrm{O} 2$ of the active site mannose in GH99 endo- $\alpha 1,2$-mannosidases (37). Thus the provision of catalytic groups by the substrate is not without precedent. The environment of Asp142 in BT3780 is not obviously apolar, and there is no residue that could act as a direct $\mathrm{pKa}$ modulator of the aspartate. Thus, the identity of 
the catalytic acid of BT3780 remains opaque. It is possible that BT3780 lacks a canonical catalytic acid, which may explain the very modest activity displayed by the enzyme.

In GH130 mannoside phosphorylases the phosphate acts as the nucleophile mounting a direct nucleophilic attack on the anomeric carbon. In inverting glycoside hydrolases an activated water molecule acts as the catalytic nucleophile. In BT3780 the glutamates Glu227 and Glu268 lie on the appropriate face of Man1 to facilitate nucleophilic attack by water at the anomeric centre. The carboxylates of both Glu227 and Glu268 hydrogen bond to the $\alpha$ linked $\mathrm{O} 1$ hydroxyl of the mannoside with distances around $2.7 \AA$, Fig. 5, and either could potentially activate a water molecule in the single-displacement mechanism. A similar pair of carboxylic amino acids also hydrogen bond to the catalytic nucleophilic water of inverting GH67 $\alpha$-glucuronidases, making the assignment of the catalytic base difficult (38). The mutation of both glutamates in BT3780 to Gln resulted in a relatively modest reduction in catalytic activity, 30-fold for Glu227 and 200fold for Glu268. Substitution of the catalytic residues of glycoside hydrolases generally results in an effectively inactive enzyme $(39,40)$, however, mutation of the candidate catalytic base of several inverting glycanases did not result in complete loss of enzymatic activity enzymatic activity $(41,42)$. It is possible that the Glu227/Glu268 pair influences the position and $\mathrm{pK}_{\mathrm{a}}$ of the other, and thus both residues may contribute to the function of the catalytic base. Mutation of either of these residues could increase the polarity of the other enabling it to fulfil a catalytic base function. Indeed, in retaining glycanases mutating the catalytic nucleophile or occupation of the active site with substrate results in the deprotonation of the catalytic acid/base, which thus functions exclusively as a base $(43,44)$. The redundant identity of the catalytic base in BT3780 is consistent with the complete loss in activity only when both glutamates were substituted for glutamine, Table 3.

Functional Phylogeny: This report provides functional insight into the phylogeny of GH130. In a previous study this family was classified into two distinct subfamilies, GH130_1, GH130_2, while the other sequences were too heterogeneous to be grouped into a single subfamily and were thus defined as GH130_NC (18). To date, the enzymes characterised from GH130_1 and GH130_2 are mannoside phosphorylases. In these enzymes, phosphate, which comprises the catalytic nucleophile, is positioned below the $\alpha$-face of the -1 Man and makes polar interactions with three basic residues, Fig. 6. Members of the GH130_NC grouping, which includes BT3780 and BACOVA_03624, lacked the three basic residues that interact with phosphate in mannoside phosphorylases, and it was proposed that these enzymes might be glycoside hydrolases (18). The data published here is entirely consistent with this hypothesis. To evaluate further this proposal the biochemical properties of another member of GH130_NC, BACOVA_03624 from B. ovatus, were evaluated. The data show that the enzyme is also a $\beta$-1,2-mannosidase Table 2, supporting the functional classification of the GH130_NC grouping as $\beta$-mannosidases. Apart from the acidic/basic residue substitution, the other residues that bind to the 1 Man in BT3780 are conserved in mannoside phosphorylases, Fig. 6A and Fig. 7.This suggests that the boat conformation of the bound mannose within GH130 enzymes is independent of hydrolytic or phosphorolytic cleavage of the glycosidic bond.

Another distinguishing feature between GH130_NC and the two GH130 subfamilies GH130_1 and GH130_2, is a tyrosine/glutamate substitution adjacent to the putative catalytic acid. It was previously proposed that the glutamate was the catalytic base (18), when no GH130 structure in complex with substrates was available. The residue in BT3780 (Glu141), however, interacts with O4 and $\mathrm{O} 6$ of mannose at the +1 subsite, and these hydrogen bonds replace the partial hydrophobic platform afforded by the tyrosine in GH130_1/2 enzymes, Fig. 6B. This glutamate is thus not in an appropriate position to act as the catalytic base.

In general the +1 subsite of GH130 enzymes are not highly conserved. This likely reflects the different specificities displayed by this family in which the scissile linkage can be $\beta-1,2$ or $\beta$ 1,4 , and the +1 sugar Glc, Man or GlcNAc. This is exemplified by BT3780 and BF0772, which 
target $\beta-1,2$ Man-Man and $\beta-1,4$ Man-Glc linkages, respectively. Consequently, the sugars in the +1 subsite of these two enzymes are in a perpendicular orientation and rotated with respect to each other. Nevertheless Arg89, which interacts with $\mathrm{O} 3$ and $\mathrm{O} 4$ of Man2 in BT3780, is conserved in BF0772 where the basic residue makes hydrogen bonds with equatorial $\mathrm{O} 2$ and $\mathrm{O} 3$ of Glc, Fig. 6B, and explains why the $B$. fragilis enzyme does not hydrolyse Man- $\beta-1,4-$ Man linkages. The other residue that makes polar contacts with Glc at the +1 subsite of BF0772 is Arg94. Although this amino acid is conserved in BT3780 (Arg101), the basic residue does not interact with Man2 and is not invariant in GH130, Fig. 7.

A key specificity determinant in BT3780 is likely to be Lys199. The lysine is the only residue that interacts with $\mathrm{O} 2$ of Man2, Fig. 5, and thus is likely to confer specificity for Man$\beta 1,2-M a n$ linkages. Indeed, Lys199 is conserved in the other three enzymes that are known to target Man- $\beta 1,2-M a n$ linkages, Fig. 7. These enzymes display mannosidase (BACOVA_03624), Table 2, and mannoside phosphorylase (Teth514_1788 and Teth514_1789) activities (13). The basic residue, however, is not conserved in mannoside phophorylases that target $\beta 1$,4-Man linkages, irrespective of the nature of the +1 sugar, Fig. 7.

To conclude, this report supports the hypothesis that the GH130 family contains glycoside hydrolases in addition to mannoside phosphorylases. The two characterised GH130 mannosidases target Man- $\beta 1,2-$ Man linkages. The predicted GH130 glycoside hydrolases, based on substitution of basic residues with glutamates, also contain the lysine $\beta 1,2-M a n$ specificity determinant. It remains unclear whether other GH130 glycoside hydrolases display additional specificities. The catalytic efficiency of BT3780 is modest, around 1000- fold lower than typical glycosidases. It is possible that this reflects in part the absence of a canonical catalytic acid leading to a low $k_{\text {cat }}$. In a recent study it was shown that $B$. thetaiotaomicron degrades yeast mannan through a selfish mechanism, which requires slow acting surface enzymes exemplified by the $\beta 1,2$-mannosidase described here (21). It is also possible that whilst BT3780 is active on the Man- $\beta 1,2-$ Man oligosaccharides of $C$. albicans mannan, its true substrate is a different fungal cell wall, which contains $\beta$-Man in an alternative context. Although little data is available on the fine structure of the cell wall mannans of other gut fungi, it should be noted that the Agaricus brasiliensis cell wall contains sulphated $\beta 1,3-G l c-\beta 1,2-M a n \quad(45)$, while Hericium erinaceus produces $\beta$-1,3-branched$\beta$-1,2-mannan (46). While the biological rationale for both $\beta$-mannosidases and $\beta$ mannoside phosphorylases in GH130 is unclear, it should be noted that the phosphorylases are cytoplasmic while the hydrolases are secreted. These different cellular locations suggest that the mannosidases target complex substrates that cannot be imported into the periplasm, while the phosphorylases, using intracellular inorganic phosphate, cleave and activate the glycone sugar enabling the phosphorylated molecule to enter cytoplasmic metabolic pathways.

Based on the presence of signal peptide, the absence of the three basic residues that interact with phosphate in mannoside phosphorylases, conservation of the motifs comprising the predicted catalytic base of $\beta$-mannosidases, and of the lysine that confers linkage specificity, it is thus now possible to predict the catalytic mechanism and the $\beta$-mannoside substrates of the hundreds of uncharacterized enzymes within GH130. As many of these enzymes, exemplified by BT3780 and BACOVA_03624, are highly prevalent in the human gut microbiome, these data provide insight into glycan utilization in this microbial ecosystem.

Acknowledgments: We cordially thank Angeline Rizzo for technical assistance and Dr Corrine Wills, School of Chemistry for expert assistance with NMR experiments. We thank the Diamond Light Source for access to beamline IO4-1 (MX-9948) that contributed to the results presented here.Financial support for HJG, AB, FC and ECLwas from the Welcome Trust (WT097907AIA) and AMD from the BBSRC (BB/K016393/1). GJD. was supported by grants from the European Research Council "Glycopoise" and by the BBSRC (BB/G016127/1). 
Conflict of interest: The authors declare that they have no conflicts of interest with the contents of this article.

Authors contributions: FC, Biochemistry of BT3780 and BACOVA_03624. AB, solved the crystal structure of BT3780. SL, expressed and purified BACOVA_03624. AMD, prepared substrates for the work. GJD, intellectual insight into enzyme function. HJG, supervised the work and contributed to writing the manuscript. GP-V, contributed to writing the paper and in characterizing BACOVA_03624. ECL, crystallized BT3780, contributed to the design of experiments and in the writing of the paper. All authors reviewed the results and approved the final version of the manuscript.

\section{REFERENCES}

1. Himmel, M. E., and Bayer, E. A. (2009) Lignocellulose conversion to biofuels: current challenges, global perspectives. Curr. Opin. Biotechnol. 20, 316-317

2. Gilbert, H. J. (2010) The biochemistry and structural biology of plant cell wall deconstruction. Plant. Physiol. 153, 444-455

3. Lombard, V., Golaconda Ramulu, H., Drula, E., Coutinho, P. M., and Henrissat, B. (2014) The carbohydrate-active enzymes database (CAZy) in 2013. Nucleic Acids Res. 42, D490-495

4. Brett, C. T., and Waldren, K. (1996) Physiology and Biochemistry of Plant Cell Walls. Topics in Plant Functional Biology, Chapman and Hall, London

5. Molinari, M. (2007) N-glycan structure dictates extension of protein folding or onset of disposal. Nat. Chem. Biol. 3, 313-320

6. Gorin, P. A., and Spencer, J. F. (1968) Structural chemistry of fungal polysaccharides. Adv. Carbohydr. Chem. Biochem. 23, 367-417

7. Jouault, T., El Abed-El Behi, M., Martinez-Esparza, M., Breuilh, L., Trinel, P. A., Chamaillard, M., Trottein, F., and Poulain, D. (2006) Specific recognition of Candida albicans by macrophages requires galectin-3 to discriminate Saccharomyces cerevisiae and needs association with TLR2 for signaling. J. Immunol. 177, 4679-4687

8. Li, R. K., and Cutler, J. E. (1993) Chemical definition of an epitope/adhesin molecule on Candida albicans. J. Biol. Chem. 268, 18293-18299

9. Ralton, J. E., Naderer, T., Piraino, H. L., Bashtannyk, T. A., Callaghan, J. M., and McConville, M. J. (2003) Evidence that intracellular beta1-2 mannan is a virulence factor in Leishmania parasites. J. Biol. Chem. 278, 40757-40763

10. Barras, F., Bortoli-German, I., Bauzan, M., Rouvier, J., Gey, C., Heyraud, A., and Henrissat, B. (1992) Stereochemistry of the hydrolysis reaction catalyzed by endoglucanase Z from Erwinia chrysanthemi. FEBS Lett. 300, 145-148

11. Bolam, D. N., Hughes, N., Virden, R., Lakey, J. H., Hazlewood, G. P., Henrissat, B., Braithwaite, K. L., and Gilbert, H. J. (1996) Mannanase A from Pseudomonas fluorescens ssp. cellulosa is a retaining glycosyl hydrolase in which E212 and E320 are the putative catalytic residues. Biochemistry 35, 16195-16204

12. Zhang, Y., Ju, J., Peng, H., Gao, F., Zhou, C., Zeng, Y., Xue, Y., Li, Y., Henrissat, B., Gao, G. F., and Ma, Y. (2008) Biochemical and structural characterization of the intracellular mannanase AaManA of Alicyclobacillus acidocaldarius reveals a novel glycoside hydrolase family belonging to clan GH-A. J. Biol. Chem. 283, 31551-31558

13. Chiku, K., Nihira, T., Suzuki, E., Nishimoto, M., Kitaoka, M., Ohtsubo, K., and Nakai, H. (2014) Discovery of two beta-1,2-mannoside phosphorylases showing different chain-length specificities from Thermoanaerobacter sp. X-514. PLoS One 9, e114882

14. Kawahara, R., Saburi, W., Odaka, R., Taguchi, H., Ito, S., Mori, H., and Matsui, H. (2012) Metabolic mechanism of mannan in a ruminal bacterium, Ruminococcus albus, involving two mannoside phosphorylases and cellobiose 2-epimerase: discovery of a new carbohydrate phosphorylase, beta-1,4-mannooligosaccharide phosphorylase. J. Biol. Chem. 287, 4238942399

15. Nihira, T., Suzuki, E., Kitaoka, M., Nishimoto, M., Ohtsubo, K., and Nakai, H. (2013) Discovery of beta-1,4-D-mannosyl-N-acetyl-D-glucosamine phosphorylase involved in the metabolism of N-glycans. J. Biol. Chem. 288, 27366-27374 
16. Senoura, T., Ito, S., Taguchi, H., Higa, M., Hamada, S., Matsui, H., Ozawa, T., Jin, S., Watanabe, J., and Wasaki, J. (2011) New microbial mannan catabolic pathway that involves a novel mannosylglucose phosphorylase. Biochem. Biophys. Res. Commun. 408, 701-706

17. Jaito, N., Saburi, W., Odaka, R., Kido, Y., Hamura, K., Nishimoto, M., Kitaoka, M., Matsui, H., and Mori, H. (2014) Characterization of a thermophilic 4-O-beta-D-mannosyl-D-glucose phosphorylase from Rhodothermus marinus. Biosci. Biotechnol. Biochem. 78, 263-270

18. Ladeveze, S., Tarquis, L., Cecchini, D. A., Bercovici, J., Andre, I., Topham, C. M., Morel, S., Laville, E., Monsan, P., Lombard, V., Henrissat, B., and Potocki-Veronese, G. (2013) Role of glycoside phosphorylases in mannose foraging by human gut bacteria. J. Biol. Chem. 288, 32370-32383

19. Ladeveze, S., Cioci, G., Roblin, P., Mourey, L., Tranier, S., and Potocki-Veronese, G. (2015) Structural bases for N-glycan processing by mannoside phosphorylase. Acta Crystallogr. D 71, 1335-1346

20. Nakae, S., Ito, S., Higa, M., Senoura, T., Wasaki, J., Hijikata, A., Shionyu, M., and Shirai, T. (2013) Structure of novel enzyme in mannan biodegradation process 4-O-beta-D-mannosyl-Dglucose phosphorylase MGP. J. Mol. Biol. 425, 4468-4478

21. Cuskin, F., Lowe, E. C., Temple, M. J., Zhu, Y., Cameron, E. A., Pudlo, N. A., Porter, N. T., Urs, K., Thompson, A. J., Cartmell, A., Rogowski, A., Hamilton, B. S., Chen, R., Tolbert, T. J., Piens, K., Bracke, D., Vervecken, W., Hakki, Z., Speciale, G., Munoz-Munoz, J. L., Day, A., Pena, M. J., McLean, R., Suits, M. D., Boraston, A. B., Atherly, T., Ziemer, C. J., Williams, S. J., Davies, G. J., Abbott, D. W., Martens, E. C., and Gilbert, H. J. (2015) Human gut Bacteroidetes can utilize yeast mannan through a selfish mechanism. Nature 517, 165-169

22. Sherman, F. (1991) Getting started with yeast. Methods Enzymol. 194, 3-21

23. Kabsch, W. (2010) XDS. Acta Crystallogr. D 66, 125-132

24. Evans, P. R. (2011) An introduction to data reduction: space-group determination, scaling and intensity statistics. Acta Crystallogr. D 67, 282-292

25. Evans, P. R. (2006) Scaling and assessment of data quality. Acta Crystallogr. D 62, 72-82

26. Emsley, P., and Cowtan, K. (2004) Coot: model-building tools for molecular graphics. Acta Crystallogr. D 60, 2126-2132

27. Vagin, A. A., Steiner, R. A., Lebedev, A. A., Potterton, L., McNicholas, S., Long, F., and Murshudov, G. N. (2004) REFMAC5 dictionary: organization of prior chemical knowledge and guidelines for its use. Acta Crystallogr. D 60, 2184-2195

28. Winn, M. D., Ballard, C. C., Cowtan, K. D., Dodson, E. J., Emsley, P., Evans, P. R., Keegan, R. M., Krissinel, E. B., Leslie, A. G., McCoy, A., McNicholas, S. J., Murshudov, G. N., Pannu, N. S., Potterton, E. A., Powell, H. R., Read, R. J., Vagin, A., and Wilson, K. S. (2011) Overview of the CCP4 suite and current developments. Acta Crystallogr. D 67, 235-242

29. Chen, V. B., Arendall, W. B., III, Headd, J. J., Keedy, D. A., Immormino, R. M., Kapral, G. J., Murray, L. W., Richardson, J. S., and Richardson, D. C. (2010) MolProbity: all-atom structure validation for macromolecular crystallography. Acta Crystallogr. D 66, 12-21

30. Miyakawa, Y., Kuribayashi, T., Kagaya, K., Suzuki, M., Nakase, T., and Fukazawa, Y. (1992) Role of specific determinants in mannan of Candida albicans serotype A in adherence to human buccal epithelial cells. Infect. Immun. 60, 2493-2499

31. Neer, E. J., and Smith, T. F. (1996) G protein heterodimers: new structures propel new questions. Cell 84, 175-178

32. Fulop, V., Bocskei, Z., and Polgar, L. (1998) Prolyl oligopeptidase: an unusual beta-propeller domain regulates proteolysis. Cell 94, 161-170

33. Davies, G. J., Wilson, K. S., and Henrissat, B. (1997) Nomenclature for sugar-binding subsites in glycosyl hydrolases. Biochem. J. 321, 557-559

34. Ducros, V. M., Zechel, D. L., Murshudov, G. N., Gilbert, H. J., Szabo, L., Stoll, D., Withers, S. G., and Davies, G. J. (2002) Substrate distortion by a beta-mannanase: snapshots of the Michaelis and covalent-intermediate complexes suggest a $\mathrm{B}(2,5)$ conformation for the transition state. Angew. Chem. Int. Ed. Engl. 41, 2824-2827

35. Tailford, L. E., Offen, W. A., Smith, N. L., Dumon, C., Morland, C., Gratien, J., Heck, M. P., Stick, R. V., Bleriot, Y., Vasella, A., Gilbert, H. J., and Davies, G. J. (2008) Structural and 
biochemical evidence for a boat-like transition state in beta-mannosidases. Nat. Chem. Biol. $\mathbf{4}$, 306-312

36. Terwisscha van Scheltinga, A. C., Armand, S., Kalk, K. H., Isogai, A., Henrissat, B., and Dijkstra, B. W. (1995) Stereochemistry of chitin hydrolysis by a plant chitinase/lysozyme and $\mathrm{X}$-ray structure of a complex with allosamidin: evidence for substrate assisted catalysis. Biochemistry 34, 15619-15623

37. Thompson, A. J., Williams, R. J., Hakki, Z., Alonzi, D. S., Wennekes, T., Gloster, T. M., Songsrirote, K., Thomas-Oates, J. E., Wrodnigg, T. M., Spreitz, J., Stutz, A. E., Butters, T. D., Williams, S. J., and Davies, G. J. (2012) Structural and mechanistic insight into N-glycan processing by endo-alpha-mannosidase. Proc. Natl. Acad. Sci. USA 109, 781-786

38. Nurizzo, D., Nagy, T., Gilbert, H. J., and Davies, G. J. (2002) The structural basis for catalysis and specificity of the Pseudomonas cellulosa alpha-glucuronidase, GlcA67A. Structure 10, 547-556

39. Charnock, S. J., Lakey, J. H., Virden, R., Hughes, N., Sinnott, M. L., Hazlewood, G. P., Pickersgill, R., and Gilbert, H. J. (1997) Key residues in subsite F play a critical role in the activity of Pseudomonas fluorescens subspecies cellulosa xylanase A against xylooligosaccharides but not against highly polymeric substrates such as xylan. J. Biol. Chem. 272, 2942-2951

40. Hogg, D., Woo, E. J., Bolam, D. N., McKie, V. A., Gilbert, H. J., and Pickersgill, R. W. (2001) Crystal structure of mannanase 26A from Pseudomonas cellulosa and analysis of residues involved in substrate binding. J. Biol. Chem. 276, 31186-31192

41. Kostylev, M., and Wilson, D. B. (2011) Determination of the catalytic base in family 48 glycosyl hydrolases. Appl. Environ. Microbiol. 77, 6274-6276

42. Fujimoto, Z., Jackson, A., Michikawa, M., Maehara, T., Momma, M., Henrissat, B., Gilbert, H. J., and Kaneko, S. (2013) The structure of a Streptomyces avermitilis alpha-L-rhamnosidase reveals a novel carbohydrate-binding module CBM67 within the six-domain arrangement. $J$. Biol. Chem. 288, 12376-12385

43. Hancock, S. M., Vaughan, M. D., and Withers, S. G. (2006) Engineering of glycosidases and glycosyltransferases. Curr. Opin. Chem. Biol. 10, 509-519

44. McIntosh, L. P., Hand, G., Johnson, P. E., Joshi, M. D., Korner, M., Plesniak, L. A., Ziser, L., Wakarchuk, W. W., and Withers, S. G. (1996) The pKa of the general acid/base carboxyl group of a glycosidase cycles during catalysis: a 13C-NMR study of Bacillus circulans xylanase. Biochemistry 35, 9958-9966

45. Cardozo, F. T. G. S., Camelini, C. M., Cordeiro, M. N. S., Mascarello, A., Malagoli, B. G., Larsen, I. V., Rossi, M. J., Nunes, R. J., Braga, F. C., Brandt, C. R., and Simoes, C. M. O. (2013) Characterization and cytotoxic activity of sulfated derivatives of polysaccharides from Agaricus brasiliensis. Int. J. Biol. Macromol. 57, 265-272

46. Lee, J. S., Cho, J. Y., and Hong, E. K. (2009) Study on macrophage activation and structural characteristics of purified polysaccharides from the liquid culture broth of Hericium erinaceus. Carbohyd. Polym. 78, 162-168

\section{FIGURE LEGENDS}

FIGURE 1 Schematic representation of the mannosides present in the human gut and reaction mechanisms of inverting glycoside phosphorylases and hydrolases.

A. Plant $\beta$-mannan, a hemicellulosic component of plant cell walls. B. Human $\mathrm{N}$-glycans, showing the different types of structures found on mature glycoproteins formed from a common $\mathrm{Glc}_{3} \mathrm{Man}_{9} \mathrm{GlcNAc}_{2}$ precursor. C. Yeast mannan; the structure depicted here is that of $C$. albicans, containing $\beta-1,2$-linked mannosyl units that cap the side chains of the $\alpha-1,6$ mannose backbone. D. general reaction mechanisms for inverting mannoside phosphorylases (i) and hydrolases (ii). 
FIGURE 2 HPAEC and TLC analysis of BT3780 catalyzed reactions

BT3780 was incubated with $1 \mathrm{mg} / \mathrm{ml} \mathrm{C}$. albicans mannan for up to $16 \mathrm{~h}$ as described in MATERIALS AND METHODS. Samples were removed at regular intervals and analysed by TLC and HPAEC.

\section{FIGURE 3 NMR analysis of the activity of BT3780}

${ }^{1} \mathrm{H}$ NMR spectra were recorded in $\mathrm{D}_{2} \mathrm{O}$ on a Bruker Avance III HD $500 \mathrm{MHz}$ NMR spectrometer operating at $500.15 \mathrm{MHz}$. The chemical shift is quoted in ppm relative to tetramethylsilane and each spectrum was acquired with 16 scans. The spectrum of $10 \mathrm{mg} / \mathrm{ml}$ C. albicans mannan in $20 \mathrm{mM}$ sodium

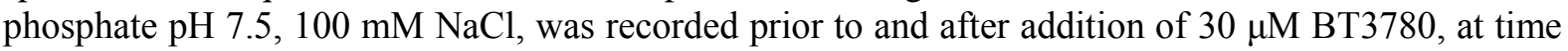
points indicated on the graph. A peak at the chemical shift corresponding to the $\mathrm{H}-1 \alpha$ proton of mannose $(5.10 \mathrm{ppm})$ was detected after 2 minutes, and mutarotation to the $\beta$-anomer was observed subsequently $(4.82 \mathrm{ppm})$, indicating that the reaction proceeds with inversion of anomeric configuration. Spectra of mannose and mannose-1-phosphate (anomeric hydrogen $5.28 \mathrm{ppm}$ ) in reaction buffer are also shown.

\section{FIGURE 4 Structure of BT3780}

Panel A is a schematic of BT3780 revealing the 5-bladed propellerfold ramp colored blue at the Nterminus to red at the $\mathrm{C}$-terminus. The ligand is shown in background as stick representation with green carbon atoms, red oxygen atoms and blue nitrogen atoms. Panel $B$ shows a surface representation of BT3780 with mannose residues bound in the active site pocket comprising the +1 and -1 subsites. The view is rotated 180 degrees along a horizontal axis compared to Panel A (ligand in foreground). The surface is represented semi-transparent in grey. The secondary structure elements are represented in red for $\alpha$-helices, yellow for $\beta$-strands and green for loops. F. Panel $C$ shows the electron density map $\left(2 F_{o}\right.$ $-F_{c}$ ) of the two mannose residues at $1.5 \sigma$. The electron density is shown in blue.

\section{FIGURE 5 The active site of BT3780}

The figure shows the three-dimensional position of the amino acids (carbons colored yellow) in the structure of BT3780 that make polar interactions (indicated by black dotted lines) with mannose (carbons colored slate green) bound in the -1 and +1 subsites.

\section{FIGURE 6 Comparison of the active site of BT3780 and a $\beta$-mannoside phosphorylase}

The figure shows an overlay of the active site of BT3780 (yellow carbons) with the $\beta$-mannoside phosphorylase BF0772 (PDB code 3WAS, blue carbons). BT3780 is in complex with two mannose residues (green) while BF0772 is bound to Man- $\beta 1,4-G l c$ (cyan carbons) and phosphate (orange). Panel $A$ and $B$ show the -1 and +1 subsites respectively.

\section{FIGURE 7 Alignment of GH130 sequences}

Members of GH130 that have been characterized and/or whose 3 dimensional structure has been determined. Enzymes in red and black cleave $\beta-1,2-$ Man and $\beta-1,4-$ Man linkages, respectively. Residues that are conserved and contribute to substrate binding in BT3780 are highlighted in yellow, the motifs that contain the residues that are predicted to comprise the catalytic base of $\beta$ mannosidases are in magenta, and the lysine that confers specificity for $\beta-1,2-$ Man linkages is in green. 
Table 1. Data statistics and refinement details.

\begin{tabular}{|c|c|}
\hline \multicolumn{2}{|r|}{ Data statistics* } \\
\hline \multicolumn{2}{|r|}{ BT_3780 } \\
\hline Beamline & IO4-1 \\
\hline Date & $22 / 05 / 14$ \\
\hline Wavelength $(\AA)$ & 0.92 \\
\hline Resolution (A) & $46.58-1.35(1.37-1.35)$ \\
\hline Space group & $\mathrm{P} 22_{1} 22_{1}$ \\
\hline \multicolumn{2}{|l|}{ Unit-cell parameters } \\
\hline $\mathrm{a}(\AA)$ & 75.77 \\
\hline b $(\AA)$ & 118.1 \\
\hline c $(\AA)$ & 126.6 \\
\hline$\alpha-\beta-\gamma\left({ }^{\circ}\right)$ & $90-90-90$ \\
\hline Unit-cell volume $\left(\AA^{3}\right)$ & 11131912 \\
\hline Solvent content $(\%)$ & 63 \\
\hline No. of measured reflections & 827701 (40692) \\
\hline No. of independent reflections & 243880 (12061) \\
\hline Completeness (\%) & $98.3(98.8)$ \\
\hline Redundancy & $3.4(3.4)$ \\
\hline Rmerge (\%) & $4.9(52.8)$ \\
\hline \multirow[t]{2}{*}{$<\mathrm{I}>/<\sigma(\mathrm{I})>$} & $10.7(1.8)$ \\
\hline & Refinement statistics* \\
\hline Rwork (\%) & 13 \\
\hline Rfree $^{\#}(\%)$ & 15 \\
\hline \multicolumn{2}{|l|}{ No. of non-H atoms } \\
\hline No. of protein, atoms & 5908 \\
\hline No. of solvent atoms & 907 \\
\hline No. of ligand atoms & 72 \\
\hline \multicolumn{2}{|c|}{ R.m.s. deviation from ideal values } \\
\hline Bond angle $\left({ }^{\circ}\right)$ & 0.014 \\
\hline Bond length $(\AA)$ & 1.7 \\
\hline \multicolumn{2}{|l|}{ Average B factor $\left(\AA^{2}\right)$} \\
\hline Protein & 15.9 \\
\hline Solvent & 35 \\
\hline Ligand & 14 \\
\hline \multicolumn{2}{|l|}{ Ramachandran plot $^{+}$, residues in } \\
\hline Most favoured regions (\%) & 100 \\
\hline \multicolumn{2}{|c|}{ *(Values in parenthesis are for the highest resolution shell). } \\
\hline \multicolumn{2}{|c|}{$\# 5 \%$ of the randomly selected reflections excluded from refinement. } \\
\hline
\end{tabular}


Table 2 Catalytic activity of GH130 $\beta$-mannosidases

\begin{tabular}{|l|l|l|}
\hline Enzyme & Substrate & Activity $\left(\boldsymbol{k}_{\text {cat }} / \boldsymbol{K}_{\mathbf{m}} \mathbf{m i n}^{\mathbf{- 1}} \mathbf{M}^{-\mathbf{1}}\right)$ \\
\hline BT3780 & Candida mannan & $6.9 \times 10^{3}$ \\
\hline BT3780 & $\beta-1,2-$-mannobiose & $2.4 \times 10^{3}$ \\
\hline BT3780 & $\beta-1,2-$ mannotriose & $3.5 \times 10^{3}$ \\
\hline BT3780 & $\beta-1,2-$-mannotetraose & $5.1 \times 10^{3}$ \\
\hline BT3780 & Man- $\beta 1,4-G l c$ & No activity \\
\hline BT3780 & Man- $\beta 1,4-G l c N A c$ & No activity \\
\hline BT3780 & Man- $\beta 1,4-G l c N A c-\beta 1,4-G l c N A c$ & No activity \\
\hline BT3780 & $\beta 1,4-M a n$ oligosaccharides DP 2-6 & No activity \\
\hline BT3780 & GlcNAc- $\beta 1,4-G l c N A c$ & No activity \\
\hline BT3780 & Man-1-phosphate & No activity \\
\hline BACOVA_03624 & Candida mannan & $6.1 \times 10^{3}$ \\
\hline BACOVA_03624 & Man- $\beta 1,4-G l c$ & No activity \\
\hline
\end{tabular}

${ }^{a}$ For substrates where the two enzymes displayed no activity assays were carried out in both $20 \mathrm{mM}$ Hepes-Na and $50 \mathrm{mM}$ sodium phosphate buffers, $\mathrm{pH}$ 7.5. 
Table 3 Relative catalytic activity of mutants of BT3780

\begin{tabular}{|c|c|}
\hline Variant of BT3780 & Relative activity \\
\hline Wild type & 1.0 \\
\hline N74A & 0.15 \\
\hline R89A & 0.025 \\
\hline E141Q & No activity \\
\hline D142N & No activity \\
\hline K199A & No activity \\
\hline E227Q & 0.032 \\
\hline E268A & 0.005 \\
\hline E268Q & 0.004 \\
\hline E227Q/E268Q & No activity \\
\hline Y302A & 0.06 \\
\hline F344A & 0.31 \\
\hline D363A & No activity \\
\hline &
\end{tabular}

The activity of the enzymes were determined using $1 \mathrm{mg} / \mathrm{ml}$ C. albicans mannan as the substrate. 
Figure 1

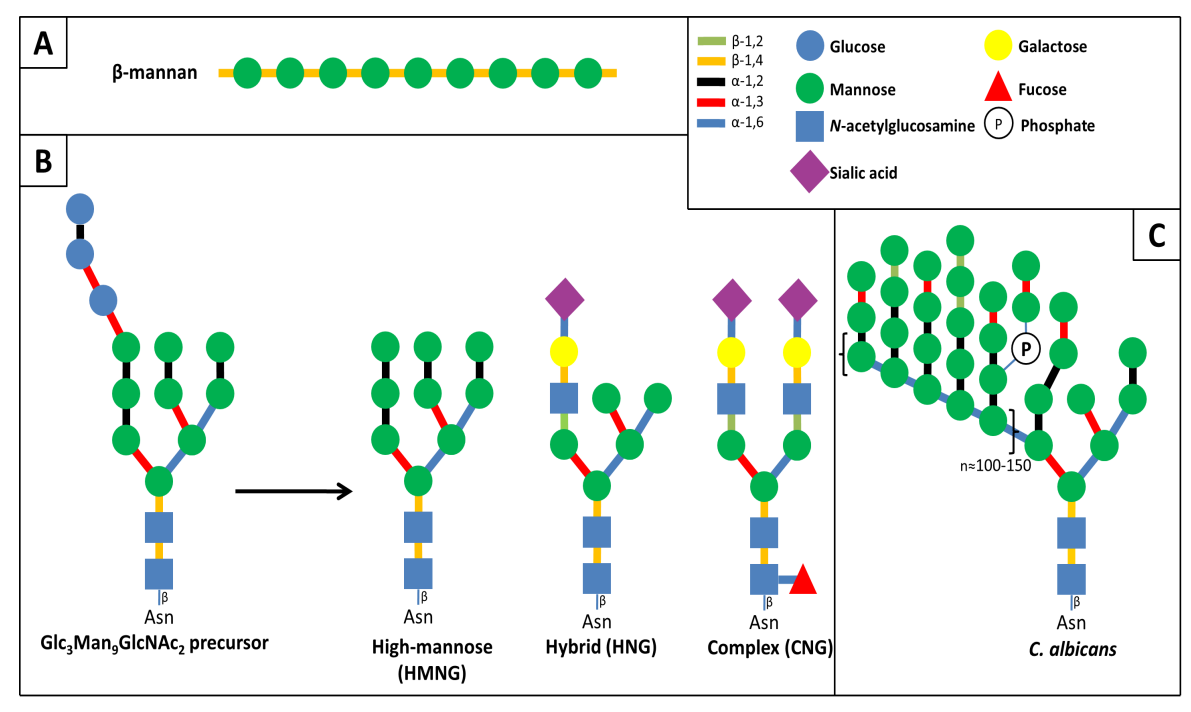

D
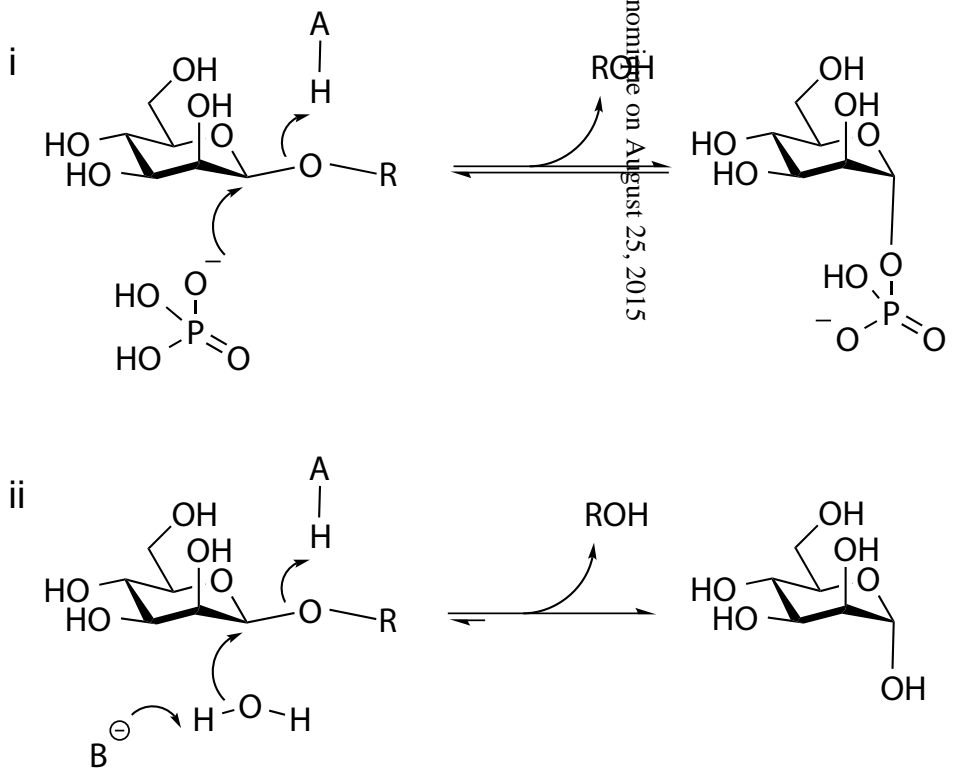
Figure 2

A

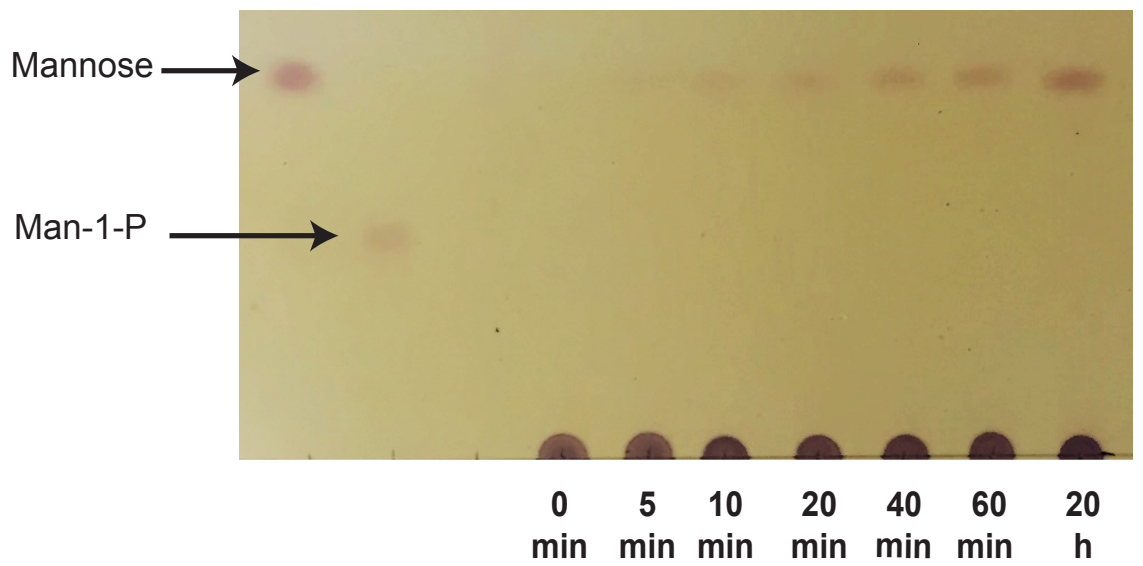

B

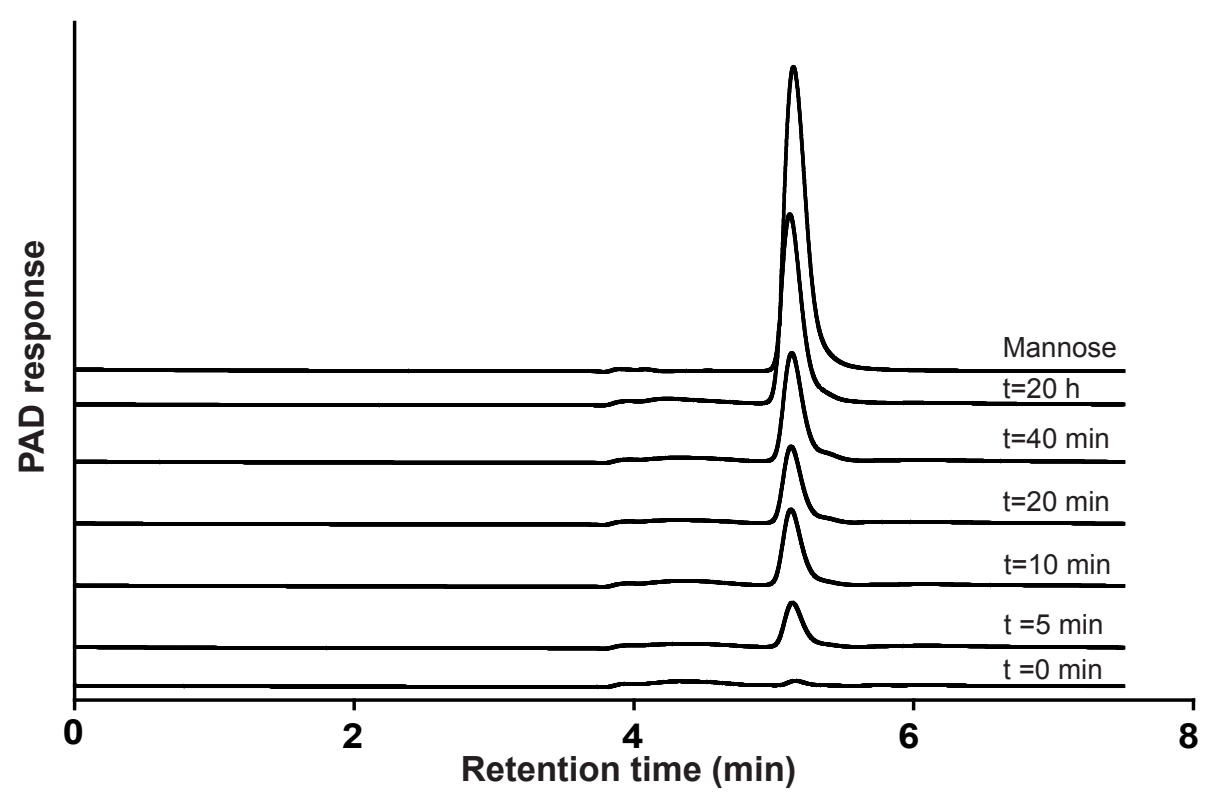


Figure 3

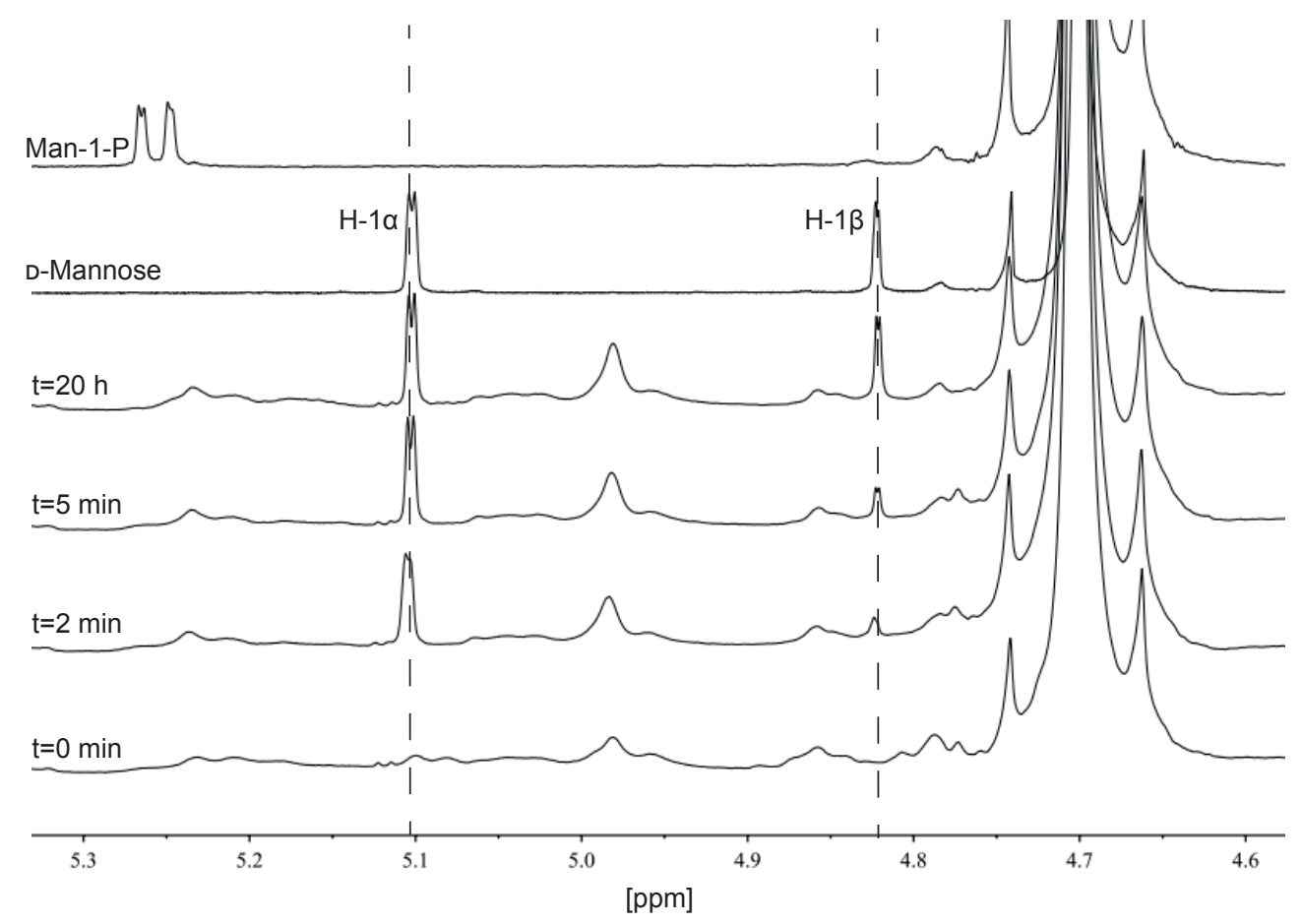


Figure 4
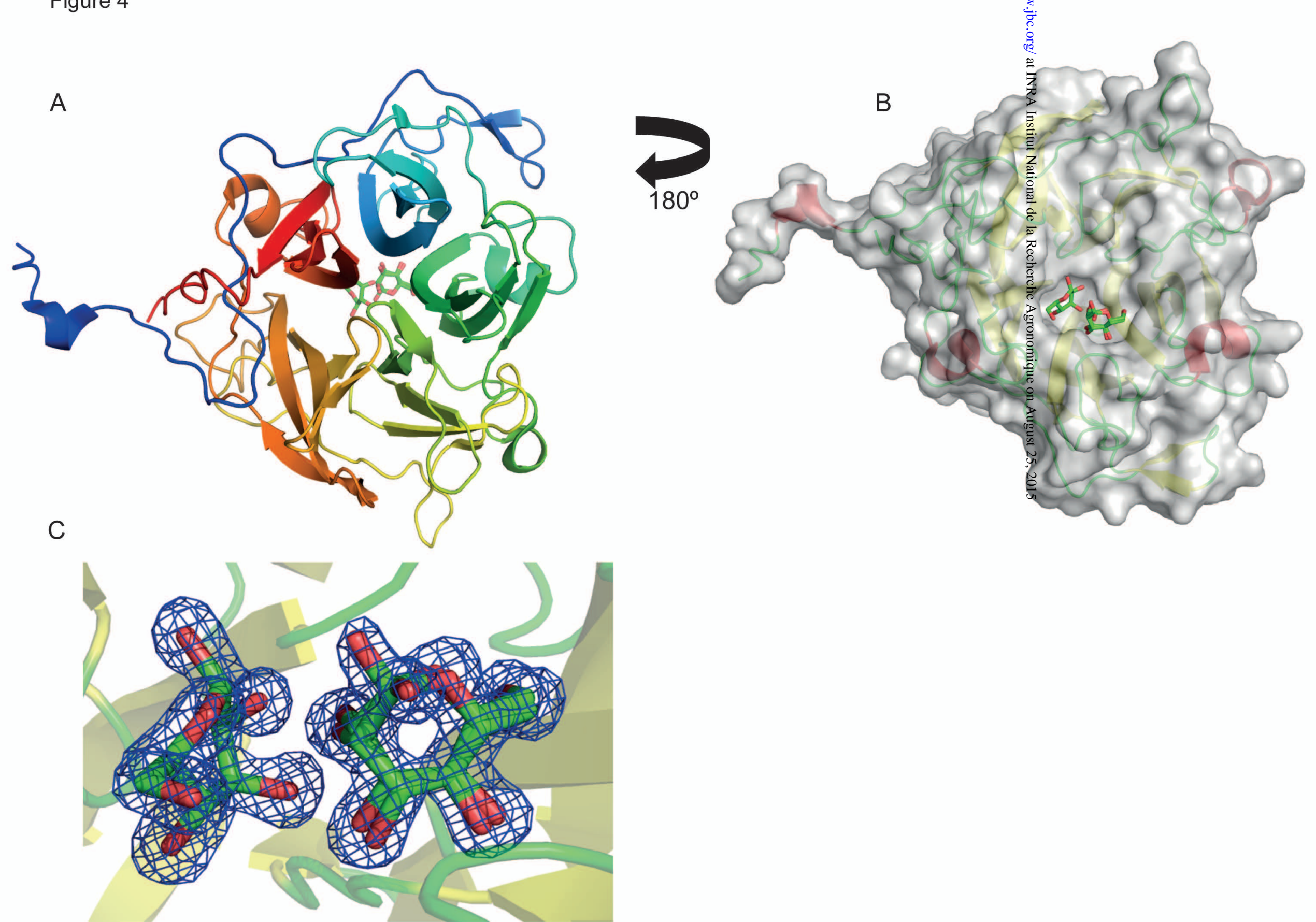
Figure 5

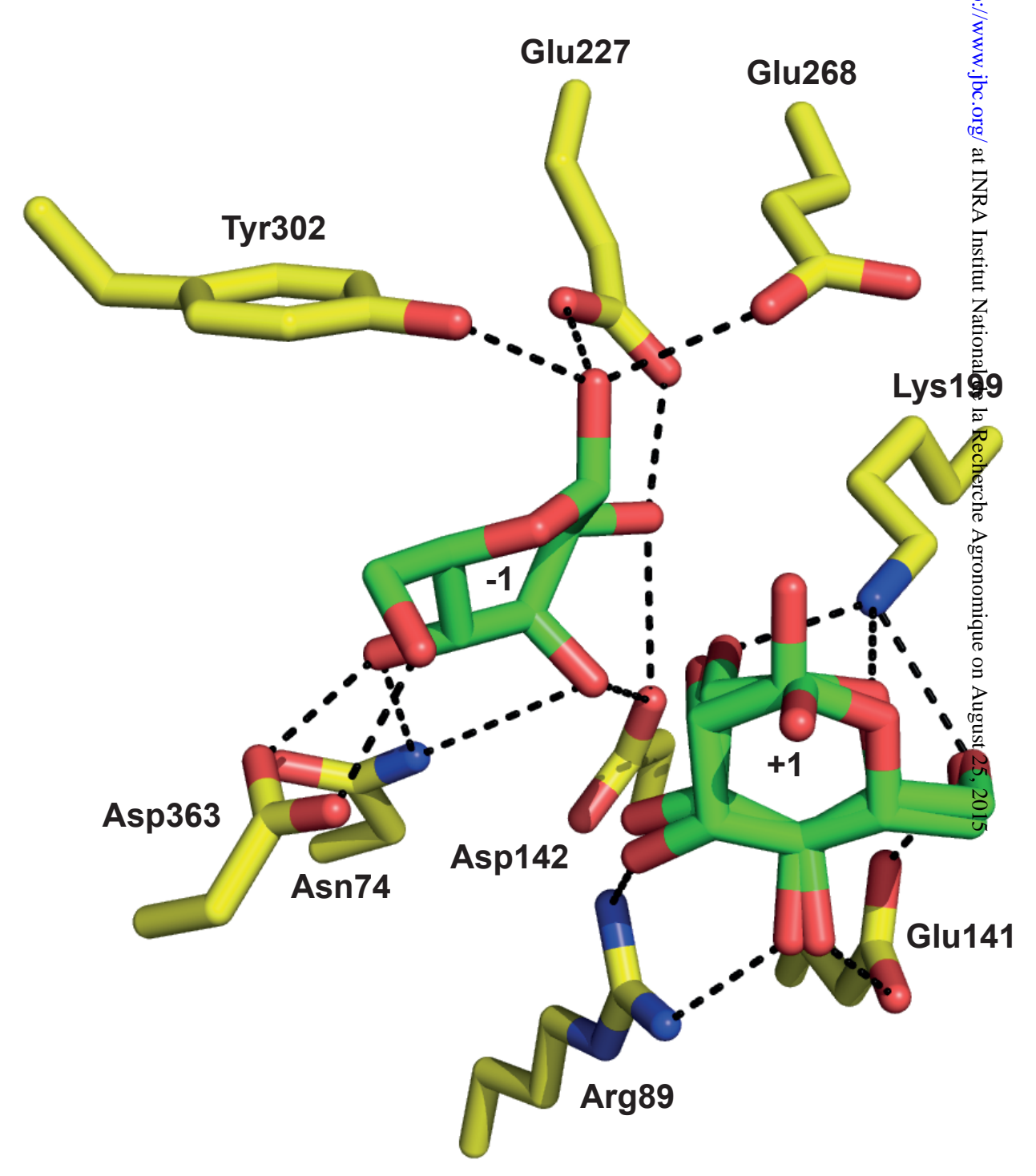


Figure 6

A

-1 subsite
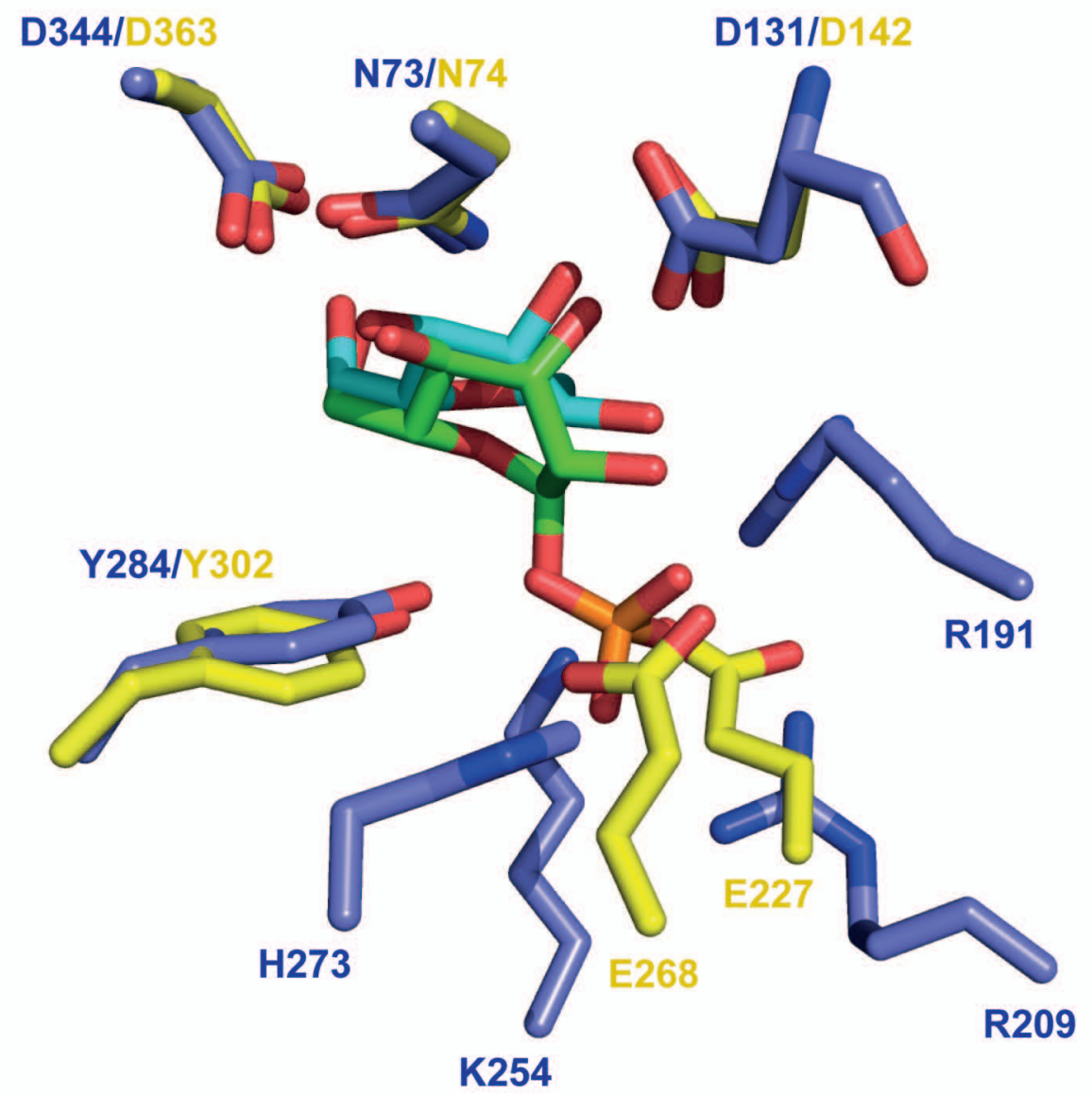

D131/D142

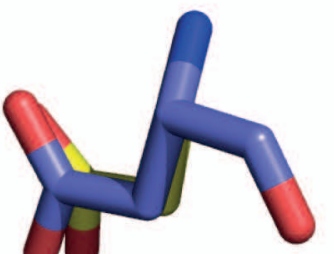

B

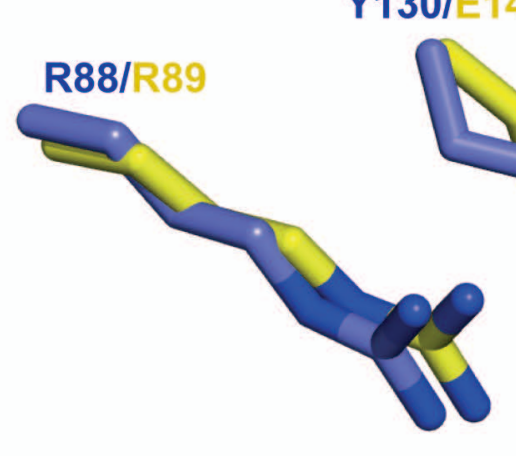

+1 subsite
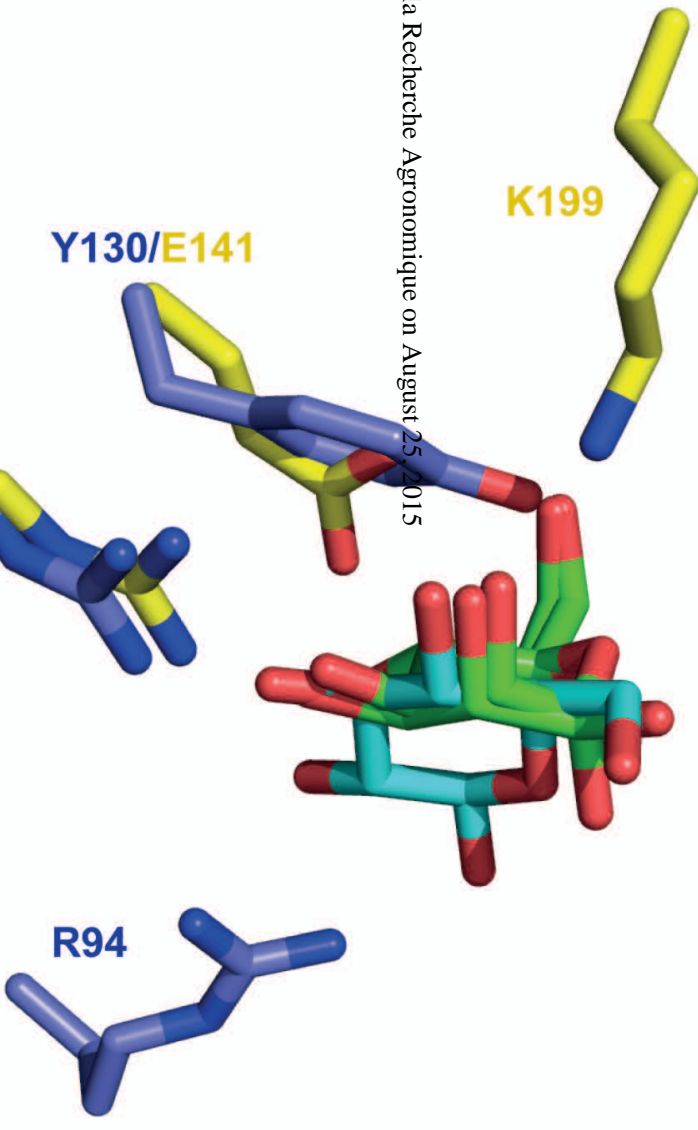
BT3780

Teth514_1789

Teth514_178

UghbmP

RaMP1

RaMP2

BACOVA_03624

BACOVA_02161

BDI 314
TM1 225

ВT3780

Teth514_1789
Teth514_1788
UghbMP -

UghbmP

BF0772

RaMP1

RACOVA 03624

BACVA- 02161

BT 4094

BDI 3141

TM1225

BT3780

Teth514_1789

Teth514_1788

UghbmP

$\mathrm{BF} 0772$

RaMP2

RaMP2
BACOVA 03624

BACOVA_0 0362

BT 4094

BDI 3141

BT3780

Teth514_1789

Teth514_178

UghbMP

BEO772

RaMP2

BACOVA 03624

BACOVA_ 02161

BT4094

TM1225
MKST---FLFLVTT-----TMMTCT--ALGQPSNDKKNVL--PDWAFGGFERPQGANPVISPIEN--------TKFYCPMTQDYVAWESNDTFNPAATLHD---GïIVVLYRAEDKSGVG 106 MFRLTR---L--MIKLKR---L---------------------------------------SSRPVLMPK------------------AENEWERAAVFNTAAIY DN---GEFHLIYRATDIGPHA 51 MSLFND---KVAKLL-A-GHEALLM--RKNEP-----VE----EGNGVITR--YRYPVLTAAHTPVFWRYDLNEETNPFLME--RIGMNATLNAGAIKWD--- 䚄YLMLVRVEGAD--- 107 MI HEKY---T--EMR-N-EQEALLS--RKNTK-----TS----FYNGIYDR--YEHPVLTREHIPLHWRYDLNKETNPFFQE-RLGINAVFNAGAIKLN--- SSRYCLVARVEGND--- 91

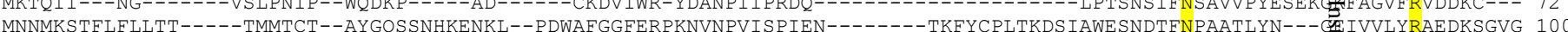
MKIKI --_G MKRKFQ---HIAYLLMVAAVITSCG--EKKOT-----SEF-PDWAWADFORPFGINP IVSPDTT-------TVFYCPMRQDSVAWESSDTFNPAATIYD---G MIKETL---LVSTFGLLGLVTVACGSOKKDQTAEAVSETISETAWCLDGFERPTGVNPVIKPLP---------TKFYCPMREDSVAWEESDTFNPAATIYD---G IVVMYRAEDNSAOG 105

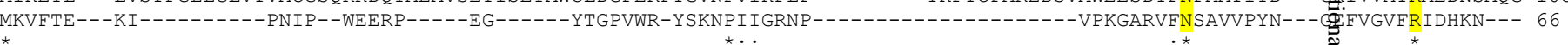

------_IGHRTSRLGYATSSDGIH-FKREKTPVFY-PDNDTQKKLEWPGGCEDPRIAVTAEGL-YVMTYTQW----------NR---HI PRLAIATSRNLKDWT: 作

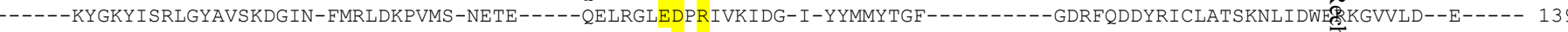
---1-1

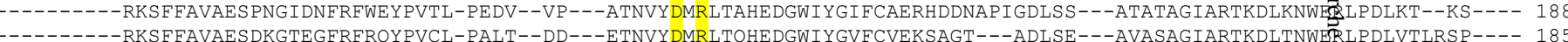

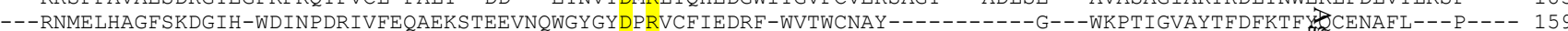

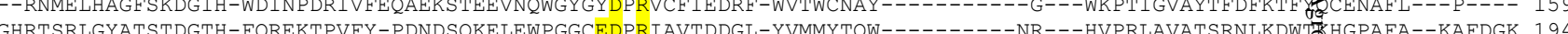
(1)

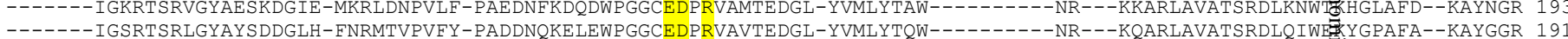
--_---_GSRTSRLGYATSTDGIH-FERDTKPAFY-PAKDNOAENECPGGTEDPRIAMTEDGT-YVLLYTOW---------NR---KVPRLAVATSKDLKHWW $\star-1$
$\star$

$$
::: \quad: \quad 9
$$

FFNLGCKSGSILTEVVNGKQVIKKIDGKYFMY

GKYVLFHRRMPD

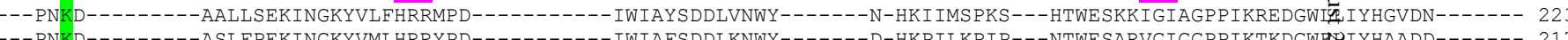

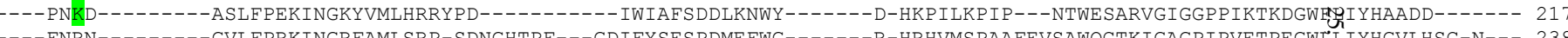

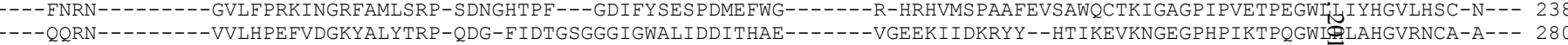
---QQRN--------VTLIPE FVDGKYAFYTRP-MDG-FIETGGSGGIGFGLADDITHAV-------TDEFRMTS IRRY--HTITESKNGAGATPIKTERGWIUNIAHGVRNTA-A--- 280

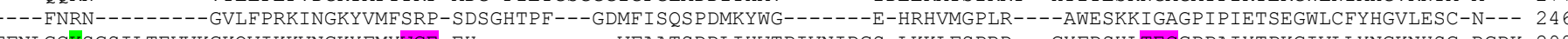
FFNLGCKKSGSILTEVVKGKQVIKKVNGKYFMYWGE-EH---------VFAATSDDLI HWTPIVNIDGS-LKKLFSPRD---GYFDSHLTECGPPAIYTPKGIVLLYNGKNHSG-RGDK 298 FNNLFCKSGSILTKLKGNQLVI DKVNGKYFMY WGE-HA---------IYAATSDNIIDWYPVLDEKNE-LMKI IQPRK---GHFDSLITECGPPAIRTKHGIVLVYNGKNSGK-TGDA 296

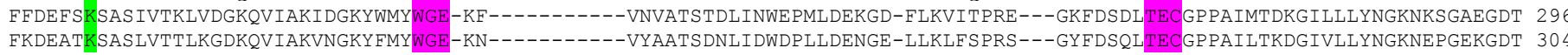
----FNRN-------GVLFPRK INGKYVMLNRP-SDNGHTPF---GDIFLSESPDMI HWG------N-HRFVLGRSSY--NWWENLKIGAGPYPIETSEGWLLIYHGVTLTC-N--- 238 $:$. $::^{\star}:$ :

RYTANVYAAGQALFDANDPTRFITRLDEPFFRPMDSFEKSGQYVDGTVFIEGMVYYK--DKWYLYYGCADSKVGMAIYNPKKR-AA-----ADPL----------------P 383 --NNVYRLGVALLDLKDPSKVIARQKEPILE PELDWEINGLVP-NVVFSCGAVEVN--DMYYVYYGAADTHIGVAVIEKEKV-KF-----

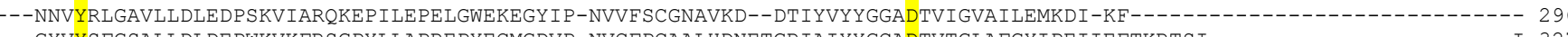
作 (1) -

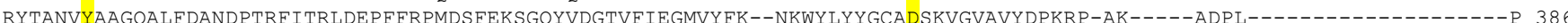

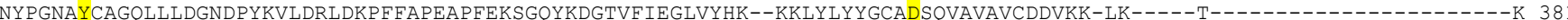

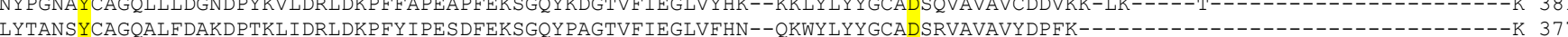

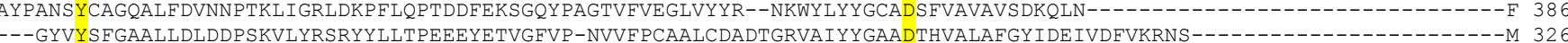




\section{Enzymology:}

The GH130 family of mannoside phosphorylases contains glycoside hydrolases that target beta-1,2 mannosidic linkages in Candida mannan

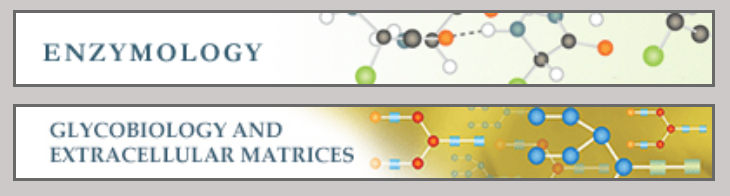

Fiona Cuskin, Arnaud Baslé, Simon

Ladevèze, Alison M. Day, Harry J. Gilbert,

Gideon J. Davies, Gabrielle Potocki-Véronèse

and Elisabeth C. Lowe

J. Biol. Chem. published online August 18, 2015

Access the most updated version of this article at doi: $10.1074 / \mathrm{jbc} . \mathrm{M} 115.681460$

Find articles, minireviews, Reflections and Classics on similar topics on the JBC Affinity Sites.

Alerts:

- When this article is cited

- When a correction for this article is posted

Click here to choose from all of JBC's e-mail alerts

This article cites 0 references, 0 of which can be accessed free at http://www.jbc.org/content/early/2015/08/18/jbc.M115.681460.full.html\#ref-list-1 